\title{
TEATRO E POLÍTICA Na AMÉRICA LATINA: NOVAS TENDÊNCIAS
}

Este número da Aletria: Revista de Estudos de Literatura, em primeiro lugar expande o conceito do que entendemos por literatura dramática e, inclusive, por teatro. A publicação se constrói como um dispositivo que pretende, junto a outros, arquitetar uma rede latino-americana no campo teatral expandido ligado às Letras e à Política. De fato, as organizadoras são, também, as coordenadoras do convênio entre a Universidad de Concepción (UdeC-Chile) e a Universidade Federal de Minas Gerais (UFMG-Brasil) na área de Letras, especificamente dentro da linha Literatura e Outras Artes.

Os novos contextos impulsionaram os artistas para a busca de outras linguagens que pudessem dar conta do campo político, entendido em toda sua amplitude. Esse fato fez com que situassem o território do teatro dentro de um mapa que expandiu suas fronteiras. Este número, nesse entendimento, entra no campo da performance, do teatro universitário e da análise de visibilidades amplas que mostram essas novas tendências.

Hoje a cena na América Latina conta com críticos capazes de criar aproximações a esse novo território no qual se situa a produção existente, ou com agentes questionadores do campo crítico. O trabalho teórico está cumprindo, assim, um papel estratégico na reivindicação desse novo lugar da arte teatral, porque possibilita entender as particularidades de seu regime de visibilidade e as decisões políticas e estéticas presentes em cada corpus específico. O ponto relevante desta reflexão é a possibilidade da troca de experiências textuais entre pesquisadores que se nutrem de (e nutrem) territórios teóricos e obras artísticas específicas.

O teatro latino-americano das últimas décadas dá visibilidade às múltiplas anomalias da arte da vida em comum, através da modalização de lugares que reclamam rupturas entre as palavras e os feitos, entre as declarações 
de igualdade na diferença e as ações que as negam. Trata-se de propostas que demandam enérgica e obstinadamente a coparticipação em um mundo comum, com igualdade de direitos, e que questionam as formas de ilusão de igualdade postas em funcionamento através da prática de todo tipo de violência, entre as quais se destaca - por seu mascaramento - a violência simbólica.

O metateatral - a integração de formas narrativas mais apegadas à realidade e, portanto, menos "fantasiosas"1 em um tecido cênico profuso de recursos teatrais atuais que sistematicamente estão questionando o lugar de partida do ato espetacular ${ }^{2}$ - é, precisamente, o que o espectador encontra-experimenta nesta cena de fronteiras expandidas.

Nessa trilha, este número da revista Aletria traz discussões relevantes para o mapeamento do campo da visibilidade estética teatral existente, e perpassa as disciplinas específicas das Letras, do Teatro e da Política. O intuito de abranger poéticas diferentes para ter uma visão de conjunto do que se está fazendo e/ou refletindo dentro do campo teatral foi amplamente atingido. Contamos, para este número, com os seguintes artigos:

- “A calma é bem-vinda para quem tem vida calma': imagens políticas na peça Erê para toda a vida ou a grande omodé", de Júlia Morena Costa, utiliza as teorias de Walter Benjamim e Didi-Huberman para analisar o texto espetacular/dramático do Bando de Teatro Olodum, Erê para toda a vida ou a grande omodé. Esta obra nasceu e foi encenada pela primeira vez há vinte anos, quando policiais disfarçados assassinaram oito jovens em situação de rua em frente à Igreja da Candelária (Rio de Janeiro). Uma fotografia da montagem desta peça foi a escolhida para nossa capa, por sua força de resistência, pelos 25 anos do grupo e pela importância do teatro negro no Brasil.

- "Agorafobia: crítica: universidad: claves para otra historia y crítica de la dramaturgia chilena", de Cristián Opazo, analisa criticamente a relação que estabeleceu, no Chile, a crítica com

\footnotetext{
${ }^{1}$ GARCÍA DEL CAMPO. El hilo rojo de la Historia, p. 3.

${ }^{2}$ TORO. Introducción: teatro como discursividad espectacular-teórica-culturalepistemológica-mediàtica-corporal, p. 10.
} 
- a produção teatral e artística realizada fora das fronteiras da Academia. Essa tendência, segundo o autor, "determina a maneira em que, muitas vezes, administramos a dimenção tropológica de nossos discursos de professores e críticos" que não contemplam os outros espaços. A essa autocrítica que engloba o coletivo, o autor denomina "agorafobia: pavor súbito aos espaços alheios". A partir desta constatação, o autor se propõe estabelecer "chaves para uma agenda de investigação atenta a reconstruir aqueles sítios de emergência das dramaturgias chilenas de cem anos que ainda não têm sido considerados". 3

- "Performance art: criação e reflexão teórico-crítica no contexto universitário", de Juliana Helena Gomes Leal, é um estudo de caso. Especificamente, sobre o trabalho com performance art desenvolvido pelos integrantes do projeto de cultura Encontros Literários na ambiência de Diamantina/ MG. Esta prática universitária, realizada no contexto da Universidade Federal dos Vales do Jequitinhonha e Mucuri (UFVJM), e seu estudo incorporam a este número da Aletria a produção teatral nascida dentro das universidades e expande as fronteiras das reflexões desde um teatro profissional até um teatro universitário, no qual um dos eixos centrais é o que a autora, adotando o conceito cunhado por Regina Melin, chama de espaços de performação.

- "O que aprendemos com o passado: Sin título, técnica mixta, revisado (2015), de Yuyachkani”, de Carla Dameane Pereira Souza, aproxima das práticas cênicas de um grupo teatral latino-americano, especificamente peruano, consolidado, os repertórios cênicos de tradição andina, que constituem material fundamental de transmissão de memória cultural. $\mathrm{O}$ texto analisa as diversas linguagens utilizadas pelo grupo com a finalidade de encenar "memórias vivas" e discutir o presente. A ênfase do artigo está na edição revisada, depois de doze anos de estreia, da peça Sin título, técnica mixta, porque, segundo a autora, "segue sendo atual e urgente. Importante

3 Tradução nossa. 
para a manutenção e revisão da memória histórica e coletiva nacional".

- "O teatro de Griselda Gambaro: novas leituras sobre antigos enfrentamentos", de Laureny Aparecida Lourenço da Silva, tem como objetivo permitir ao leitor realizar uma visita, a partir do conceito de grotesco desarticulador, ao teatro e às temáticas da dramaturga argentina Griselda Gambaro. Especificamente, o artigo analisa a peça Del sol naciente (1984), na qual fica patente a questão do poder. Lembremos que, em 1983, a ditadura vivia uma derrota militar (as Malvinas) e uma dívida externa que aumentou os conflitos sociais. Sua única saída foi entregar o poder aos civis no dia 10 de dezembro de 1983.

- "Razões práticas da teatralidade expandida de Ileana Diéguez Caballero e dois dispositivos cênicos do dramaturgo/ativista João Dias Turchi", de Jorge Alves Santana, se estabelece como o diálogo entre as reflexões de Diéguez e a prática teatral socioestética de Turchi. Prática que se situa no campo do ativismo e da intervenção. Nesse ensaio, o autor analisa, especificamente por meio de um estudo de caso (Máquina de escrever reticências e Planta), a teatralidade expandida em sua dimensão de liminalidad - conceitos desenvolvidos por Ileana Diéguez Caballero - e as ações socioestéticas.

Além dos aportes específicos do campo teatral, nesta edição temos estudos das sessões "Varia" e "Resenha" que apontam para diversos temas de interesse geral. Recuperando o diário de Cristóvão Colombo, escrito em sua primeira viagem pelo Ocidente, em 1492, Daniel Wanderson Ferreira acentua a complexidade da travessia do Mar Oceano e propõe chaves interpretativas acerca do medo, do temor, dos afetos do viajante e da tripulação. Importa-lhe esboçar, em sua proposta argumentativa, uma representação do conceito renascentista de homem.

$\mathrm{Na}$ mesma esteira reflexiva acerca dos gêneros literários que trabalham com a noção da escrita do eu e da vida, o ensaio de João Guilherme Dayrell promove um questionamento específico sobre a biografia. Para tanto, apoia-se no pensamento de Emanuele Coccia e lê O amanuense Belmiro, de Cyro dos Anjos, e Água Viva, de Clarice Lispector, como exemplos de um corte oblíquo na literatura brasileira 
ao colocarem em questão a condição autobiográfica dos escritos dos personagens.

A conhecida frase "mire e veja", do personagem Riobaldo, narrador de Grande sertão: veredas, de Guimarães Rosa, é central no texto de Christian Werner, que reconhece no refrão ressonâncias temáticas e pragmáticas. A hipótese trabalhada é a de que se trata de uma fórmula central de transmissão da experiência.

Apoiado na análise da trajetória artística do argentino Aldo Pellegrini (1930-1973), o ensaísta Guido Herzovich analisa o entrelaçamento entre a vanguarda, o mercado e o surrealismo e joga luz numa cena pouco conhecida, no Brasil, sobre este escritor experimental.

O texto que fecha este número da Aletria, que apostou na indiscernibilidade entre ética, estética e política, é uma resenha sobre o livro de Marcos Siscar lançado em 2015, intitulado Manual de flutuação para amadores. Para Eduardo Horta Nassif Veras, trata-se de uma importante inflexão na trajetória deste poeta, pois aponta para "um avanço no movimento de aproximação em zoom na direção da terra firme, como quem aprofunda o mergulho visual no nosso planeta ou como quem sobrevoa, não mais a bordo da Apolo 13 a 'terra azul por inteiro', mas como um amador que flutua baixo como uma 'bexiga de gás'”.

Se a obra de Siscar discorre sobre o chão, com distância calculada, espera-se que esta edição tenha cumprido também com o gesto de expansão de territórios da criação teatral, literária, poética, crítica, rumo ao pensamento político que almeja.

As organizadoras

\section{Referências}

TORO, Alfonso de. Introducción: teatro como discursividad espectacularteórica-cultural-epistemológica-mediàtica-corporal. In: . Estrategias postmodernas y postcoloniales en el teatro latinoamericano actual. Hibridez - Medialidad - Cuerpo. Madrid: Iberoamericana, 2004.

GARCÍA DEL CAMPO, Juan Pedro. El hilo rojo de la Historia. Nodo 5c: Contrainformación em la Red, p. 1-8, 2009. Disponível em: $<$ http://info. nodo50.org/IMG/article_PDF/El-hilo-rojo-de-la-Historia.pdf $>$. Acesso em: 14 jun. 2016. 